\title{
SYNTHESIS, CHARACTERISATION AND BIOLOGICAL EVALUATION OF NEW MIXED LIGAND COMPLEX (DERIVED FROM SCHIFF BASE)
}

\author{
P. Shabana, B.R. Chaitantya Kumar and K. Sudhakar Babu ${ }^{\bowtie}$ \\ Department of Chemistry, Sri Krishnadevaraya University, Anatapuramu 515-003, A.P. INDIA. \\ Corresponding Author: drksbabu9@gmail.com
}

\begin{abstract}
Mixed ligand complex included Schiff base derivative Ni(II)complexes(M(L1)(L2)) where L1 is the Schiff base derived from condensation between (3,4,5-Trimethoxy benzaldehyde) and 4 Amino antipyrine(4-amino-1,5dimethyl-2-phenyl-1-H-pyrazol-2-H-one(3,4,5TMBAAP) was synthesized and characterized using conventional and spectral techniques.3,4,5(TMBAAP) is taken as a primary ligand or parent ligand ( L1)and an amino acid Ltryptophan (L2)is added as the second ligand through refluxation to form mixed ligand with metal Ni(II) to form a complex. The mixed ligand complex 3, 4, 5(TMBAAPT)was characterized using ${ }^{1} \mathrm{H}-\mathrm{NMR}$, ${ }^{13} \mathrm{C}-\mathrm{NMR}$, $($ EDAX)(Energy dispersive x-ray elemental analysis),UV-visible ,FTIR,SEM techniques. The structural elucidation assessed with.respect.to.the metal complex obtained was octahedral geometry based on the analytical studies. The invitro antibacterial and antifungal assay of mixed ligand were evaluated. The details of the results are well presented in the research investigation.
\end{abstract}

Keywords: Schiff Base, EDAX, Tryptophan, Anti-bacterial, Anti-fungal Assay

RASĀYAN J. Chem., Vol. 14, No.2, 2021

\section{INTRODUCTION}

Schiff bases and their complexes are adaptable compounds made by precipitating an amino acid with a carbonyl group. The perusal of literature reveals that Schiff base complexes or azomethines and imines show virtuoso incentive activities exemplified in copious reactions. The maneuver is frequently enhanced by a result, understanding the properties of both ligands and metals requires complexation,which leads to the generation of tremendously energetic composites. ${ }^{1-2}$ The impact of metals on the biological exertion of Schiff bases and their peculiar chemical attentiveness has persuaded a substantial extension in the growth of their coordination behavior. ${ }^{3-4}$ The mixed ligand or assimilated complexes are an imperative category of coordination compounds and have captivated prominent attentiveness and are also known as azomethines and imines. ${ }^{4-9}$ It is possible to prepare a wide range of mixed ligand complexes with a single metal ion, and a colossal number of complexes can be synthesized by mixing different metal ions and could be amalgamated. This furnishes an admirable scope for the study of complex structure and concomitant correlations. A huge number of such complexes are integrated and investigated. Amid them, variegated ligands with complexes derived from tryptophan exhibit antimicrobial assay. ${ }^{10}$ Azo-methine ligands on another point of view are of the fascinating grade of ligands which have been the study of concerted examination of co-ordination amalgam of numerous variants; Schiff bases have initiated tremendous usages in extensive fields such as Biochemistry, Medical, Industries, and Laboratories. In this concern, azomethines or Schiff base ligands have revealed an influential place and are classified as monodentate, bidentate, tridentate according to their density. ${ }^{11-13}$ Azo dyes of 4-Amino antipyrine are familiar as polydentate ligands co-coordinating in neutral and ionic forms. ${ }^{14} 4$-amino antipyrine plays a vital role in numerous domains such as anti-cancer anti-inflammatory, anti-oxidant, anti-HIV have been reported earlier-tryptophan is an unusual amino acid because of the complexity of its metabolism, the variety of diseases it is involved as a pharmacological agent. ${ }^{15}$ Therefore in the present study, the author has focused on the development of mixed ligand complex 4-N-(3, 4,5Trimethoxy benzalidine-1, 5dimethyl-2-phenyl-1-H-pyrazole-3(2H) one, with metal $\mathrm{Ni}$ (II) and L-tryptophan an amino acid as a secondary ligand. The invitro antibacterial and antifungal assay of the derived complex was evaluated. 
RASĀYAN J. Chem.

Vol. 14 | No. 2 |1408-1414| April - June | 2021

\section{Materials and Methods}

\section{EXPERIMENTAL}

All chemicals were procured from mercantile sources and were utilized without atonement. Elemental analysis (EA) of $\mathrm{C}, \mathrm{H}, \mathrm{N}, \mathrm{O}$ was performed using EDAX (energy dispersive $\mathrm{x}$-ray analysis), IR spectra were recorded on Bruker Fourier Transform Infrared(FT-IR) spectrometer on potassium bromide( $\mathrm{KBr}$ ) pellet in the wave numeral radius of 4000-400 $\mathrm{cm}$.Electronic spectral studies were conducted on an Ultra Violet(UV-Visible) 1800 series, with a wavelength of 200-400 nm. NMR interpretation was chronicled on a 800MHZ-NMR spectroscope through the reference of TMS and DMSO solvent. SEM images are acquired from a scanning electron microscope. FLEX- SEM 1000 instrument.

\section{Synthesis of Primary Ligand $\left(\mathrm{L}_{1}\right)$ [TMBAAP]}

$3,4,5$ Trimethoxy benzaldehyde $(2 \mathrm{~g})(0.1 \mathrm{M})$ was taken and dissolved in $50 \mathrm{ml}$ of methanol. The 4amino-1,5-dimethyl-2-phenyl-1-H-pyrazole-3(2H)one, $(2.2 \mathrm{~g})(0.1 \mathrm{M})$ Was dissolved in $50 \mathrm{ml}$ of distilled water .These solutions were mixed in a sterilized $250 \mathrm{ml}$ round bottom flask and stirred with a magnetic rioter. This reaction mixture was excited in a water bath by refluxing for one hour. On cooling and slow evaporation at room temperature, a yellow-colored precipitate was formed. The solid outcome was isolated by clarifier and drenched many times with hot water. Then it was evaporated in a vacuum. The compound was recrystallized from methanol. The percentage of yield is $85 \%$.

\section{Synthesis of Secondary Ligand $\left(\mathrm{L}_{2}\right)$ [TMBAAPT]}

To the warm methanolic solution of $10 \mathrm{ml}$ of 4-N(3,4,5 Trimethoxy benzalidine -1,5-dimethyl-2-phenyl1-Hpyrazol-3(2H)-one)(TMBAAP) $(0.1 \mathrm{M})$ as a primary ligand was appended to $10 \mathrm{ml}$ of warm methanol suspension of Nickel sulphate $(0.75 \mathrm{~g})(0.05 \mathrm{M})$. After $30 \mathrm{~min}, 5 \mathrm{ml}$ of methanolic solution of L-tryptophan [2-amino-3-1-H-indol-3-yl-propanoic acid] (2.2g) (0.1M) amino acid was added as secondary ligand.The composition was stirred vigorously. Further, the mishmash was refluxed for about 2 hours. The resultant precipitate was altered from yellow to green-colored crystals. The obtained crystals were percolated and cleansed with warm water and dried in the void. The percentage of yield was $79 \%$. The physicochemical properties of the primary ligand and mixed ligand were given in the following table. (Table-1).

\section{Infrared Spectral Studies}

\section{RESULTS AND DISCUSSION}

The IR spectrum of primary ligand (L1) exhibited a characteristic band at $1648 \mathrm{~cm}$ and $1579 \mathrm{~cm}$ ascribed to $\sqrt{ }(\mathrm{C}=\mathrm{O})$ and $\sqrt{ }(\mathrm{C}=\mathrm{N})$ sequent. The band at 1648 is referable to the $\sqrt{ }(\mathrm{C}=\mathrm{O})$ extended quivering of azomethine ligand is conveyed to flipside terrain $1594 \mathrm{~cm}$ to $1579 \mathrm{~cm}$ indicating co-ordination of oxygen belonging to carbonyl group towards the metal ion. The presence of a band at $698 \mathrm{~cm}$ in the IR spectra is due to Metal to oxygen perpetuating vibration. The azomethine band at 1578 of Schiff base was shifted to a lower frequency ranging 1496-1452cm in the spectra of complexes confirming the contribution of the nitrogen atom belonging to the azo-methine group in co-ordination with metal. The spectrum shows welldefined peaks at (3431-3080) are attributed to $\sqrt{ }(\mathrm{O}-\mathrm{H})$ of carboxyl moiety and $\sqrt{ }(\mathrm{N}-\mathrm{OH})$ indole moiety. There was a change in frequency with a change in shape and intensity on coordination with the metal ion at $(1648-1899 \mathrm{~cm})$ indicating that the carbonyl oxygen of antipyrine has been involved in chelation. The band at $776 \mathrm{~cm}$ is related to $\sqrt{ }(\mathrm{C}=\mathrm{N})$ of tryptophan for secondary ligand. This band is shifted to $698 \mathrm{~cm}$ binding of mixed ligand therefore the IR data confirms ligands coordinate with metal complex through $\mathrm{O}$ and $\mathrm{N}$ respectively. The FTIR spectra of primary ligand (TMBAAP) and mixed ligand with the metal $\mathrm{Ni}$ (II) were represented in Fig.-1 and 2 respectively.

\section{The ${ }^{1} \mathrm{H}-\mathrm{NMR}$ and ${ }^{13} \mathrm{C}-\mathrm{NMR}$ Spectral Studies}

The ${ }^{1} \mathrm{H}-\mathrm{NMR}$ spectra data of ligand is recorded in Dimethyl sulfoxide (DMSO) solution with Tetramethylsilane (TMS) as in most criterion. The spectrum referring to ligand (TMBAAP) exhibited a signal related to one proton that appeared at $(9.69 \mathrm{ppm})$ which is assigned to $\mathrm{NH}$ proton of indole ring. The multiple signals that appeared in the region (7.50-7.26ppm) were assigned to chemical shifts of aromatic protons of naphtyl and indole ring. The signals at 3.91 are attributed to $(\mathrm{CH}-\mathrm{NH} 2)$ azo-methine 
RASĀYAN J. Chem.

Vol. 14 | No. 2 |1408-1414| April - June | 2021

moiety. For the following compound characteristic ${ }^{13} \mathrm{C}-\mathrm{NMR}$ signal of the azomethine group $(\mathrm{C}=\mathrm{NH})$ was observed at $134.97 \mathrm{ppm}$.

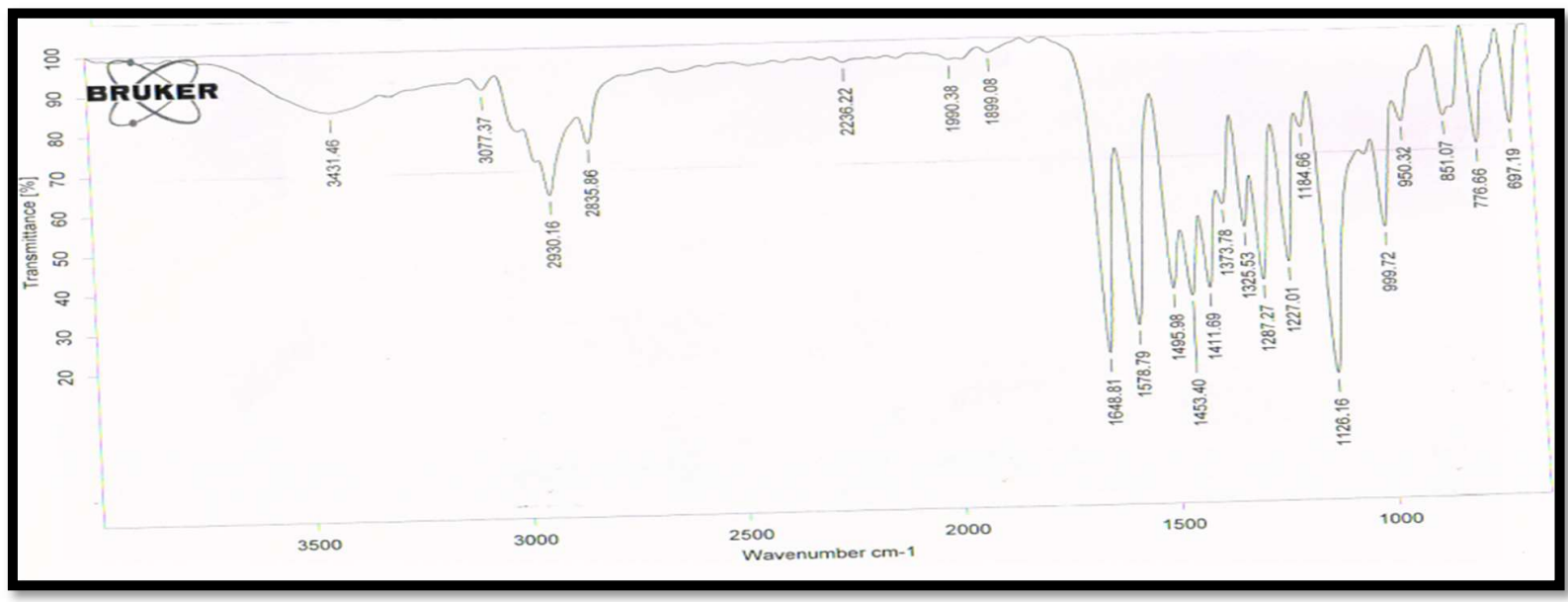

Fig.-1: FTIR Spectrum of the Ligand TMBAAP

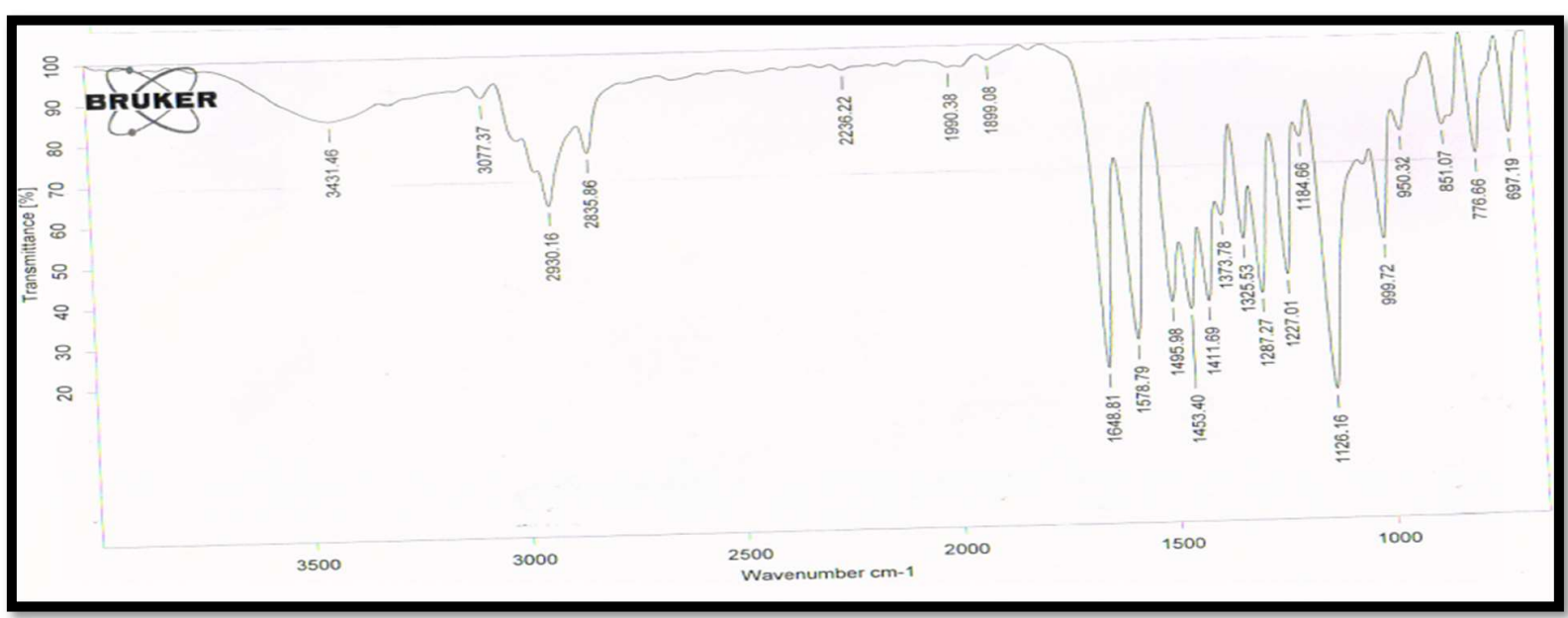

Fig.-2: FTIR Spectrum of the Mixed Ligand with Metal Complex Ni (TMBAAPT)

This characteristic peak has been seen for others at 138.4, 134.5, 135.5, 132.0, 131.5ppm respectively. Furthermore, signals attributed at 151.93, 134.97, 133.57, 129.31, 127.01, 124.46 ppm are contributed to aromatic carbon atoms reciprocally. The ${ }^{1} \mathrm{H}-\mathrm{NMR}$ spectrum and 13C- NMR spectrum of mixed ligand are shown in Fig.-3 and Fig.-4 respectively.

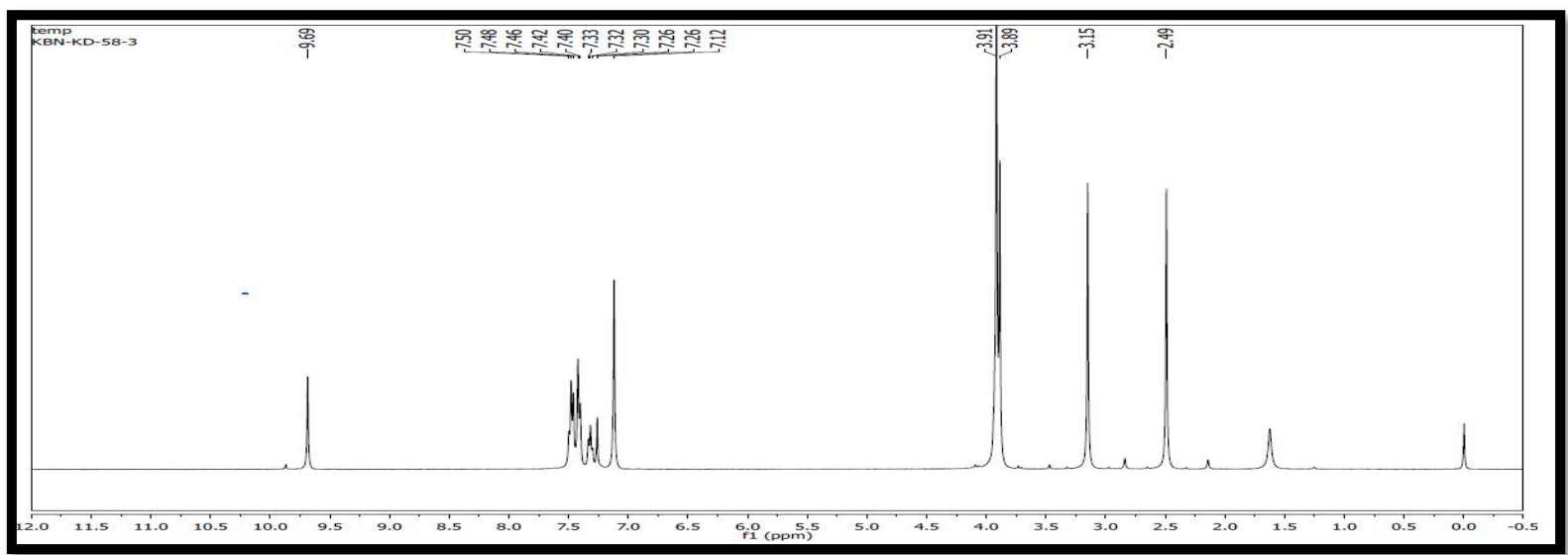

Fig-3. ${ }^{1} \mathrm{H}-\mathrm{NMR}$ Data of Ligand

1410 
RASĀYAN J. Chem.

Vol. 14 | No. 2 |1408-1414| April - June | 2021

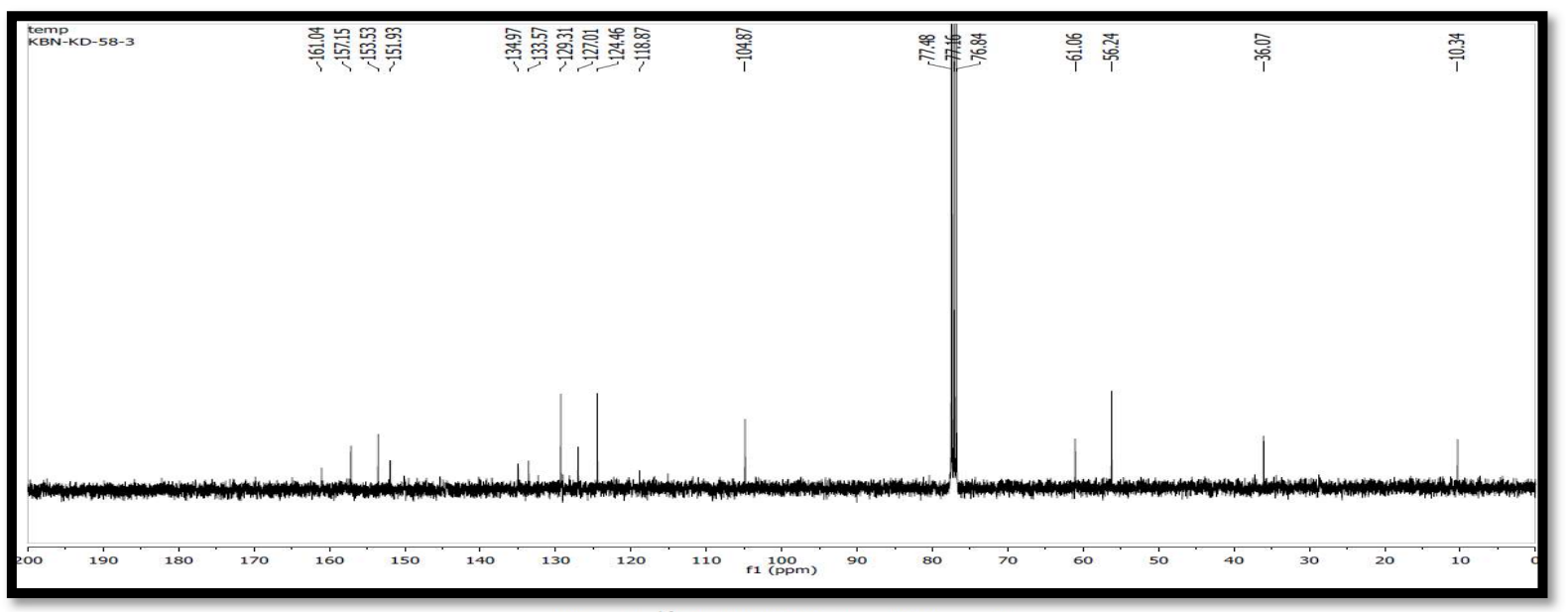

Ultraviolet (UV) Spectral Inquest

Fig.-4: ${ }^{13} \mathrm{C}-\mathrm{NMR}$ Data of Ligand

The voltaic spectral bands of ligand and its metal complexes with preliminary values are represented in Table-2 given below. To attain a wider insight into the properties of the transitions in the coordination field of prepared complexes. The UV spectrum of mixed ligand displays both band maxima at 26,798 and $39,525 \mathrm{~cm}$ corresponding to $\mathrm{n}-\pi^{*}$ and $\pi-\pi^{*}$ conversions consequently. In Ni (II) complex, both transitions appeared at $\mathrm{n}-\pi^{*}$ and $\pi-\pi^{*}$ bands at $328 \mathrm{~nm}$ and $238 \mathrm{~nm}$ are found to be shifted and raised in the region $26,168-27,289 \mathrm{~cm}$ and $39,640-45,148 \mathrm{~cm}$ compared to that of ligand. The electronic spectra of ligand (TMBAAPT) with Ni (II) were performed in methanol as reference. $\pi$ - $\pi^{*}$ transition is a resemblance of heterocyclic moiety and this transition owing to the intermolecular charge transfer taken place through azoic moiety. The absorption maximal data in $\lambda(\mathrm{nm})$ and Max $(\mathrm{cm})$ are summarized in the Table- 2 given below.

Table-1:The Physico-chemical Properties of Primary Ligand (TMBAAP) and mixed Ligand Ni(TMBAAPT)

\begin{tabular}{|c|c|c|c|c|c|c|}
\hline \multirow[t]{2}{*}{ Compound } & \multirow[t]{2}{*}{ Color } & \multirow{2}{*}{$\begin{array}{l}\text { M.P }\left[{ }^{0} \mathrm{C}\right] \\
\text { (Yield \%) }\end{array}$} & \multicolumn{4}{|c|}{ Elemental Analysis } \\
\hline & & & $\mathrm{C}$ & $\mathrm{H}$ & $\mathrm{N}$ & $\mathrm{O}$ \\
\hline $\begin{array}{c}\text { Primary } \\
\text { Ligand(TMBAAP) }\end{array}$ & Yellow & $300(84 \%)$ & 62.26 & 5.38 & 20.11 & 31.78 \\
\hline $\begin{array}{l}\text { Secondary Ligand } \\
\text { Ni(TMBAAPT) }\end{array}$ & $\begin{array}{l}\text { Olive } \\
\text { green }\end{array}$ & $210(79 \%)$ & 56.84 & 4.39 & 16.9 & 45.18 \\
\hline
\end{tabular}

Table-2: Electronic Spectral Studies

\begin{tabular}{l|c|c|l}
\hline \multirow{2}{*}{ Compounds } & \multicolumn{2}{|c|}{ Absorption } & \multicolumn{1}{c}{$\begin{array}{c}\text { Tentative } \\
\text { Assignments }\end{array}$} \\
\cline { 2 - 4 } & $\lambda(\mathrm{nm})$ & Max cm & \multicolumn{1}{|c}{$\pi^{*}$} \\
\hline \multirow{2}{*}{ Ligand( $\left.\mathrm{L}_{1}\right)$ (TMBAAP) } & 328 & 39.525 & $\pi-\pi^{*}$ \\
\cline { 2 - 4 } & 238 & 26.798 & $\mathrm{n}-\pi^{*}$ \\
\hline \multirow{2}{*}{$\mathrm{Ni}\left(\mathrm{L}_{1}\right)($ TMBAAP) } & 262 & 45.148 & $\pi-\pi^{*}$ \\
\cline { 2 - 4 } & 302 & 39.825 & $\pi-\pi^{*}$ \\
\cline { 2 - 4 } & 293 & 27.289 & $\mathrm{n}-\pi^{*}$ \\
\hline \multirow{2}{*}{$\mathrm{Ni}\left(\mathrm{L}_{1}\right)\left(\mathrm{L}_{2}\right)($ TMBAAPT) } & 225 & 40.000 & $\mathrm{n}-\pi^{*}$ \\
\cline { 2 - 4 } & 229 & 26.148 & $\mathrm{~d}-\mathrm{d}$ transition \\
\cline { 2 - 4 } & 342 & 21.739 & \\
\hline
\end{tabular}

\section{Scanning Electronic Microscope}

The scanning electron micrographs (SEM) unveil the framework of Schiff bases with Ni (II) complexes. The SEM images are taken at $15 \mathrm{kV}$ stimulated potential and amplification was fixed following the need from 150 xs to $3000 x$. In SEM images perceptible phase separations in the dense layer were observed. The province size of $2 \mu \mathrm{m}$ in ligand, $20 \mu \mathrm{m}$ in metal complex and $50 \mu \mathrm{m}$ in mixed ligand were detected. In SEM images the surface of the ligand was soft and smoothy layer, after coordination with metal there was a large macroscopic phase separation. This phase separation was minimized after the formation of a mixed ligand. Also, the snugness and softness were reduced due to the introduction of metal. It was 
RASĀYAN J. Chem.

Vol. 14 | No. 2 |1408-1414| April - June | 2021

evident that there was a substantial change in the morphology of Schiff base on complexation. The SEM images of primary ligand, a mixed ligand of the metal complex have shown in Fig.-5.

\section{Antimicrobial Assay}

Mixed Ligand derived from Schiff base was tested against bacteria and fungi. These ligands with a metal complex show anti-microbial activity. The prepared Ligand Ni[TMBAAPT] with $(150 \mu \mathrm{g} / \mathrm{ml})$ along with metal was tested in-vitro against the following microorganisms, the two bacterial species Staphylococcus aureus and salmonella typhi and two fungal species Aspergillus fumigatus and Candida albicans. The effect of the synthesized mixed ligand towards microbes is represented in Table-3. The prepared complex exhibits high anti-microbial activity than the parent ligand [TMBAAP]. The elevated exertion of the complex may be allocated to the different properties of metal ions upon chelation, it gets adsorbed on the cell wall of microorganism, causes blockage of protein synthesis, which results in an abatement of microorganism. Thus metal ions are considered as a growth-inhibitory influencer. A computative observation of the values of parent ligand with mixed ligand complex exhibits high anti-microbial assay. Using Tweed's chelation theory as a base, chelation greatly decreases the polarity of the metal ion due to biased splitting of its positive charge with the contributor cluster, as well as -negative particle demobilization on the donor group on the entire chelate ring. Furthermore, the metal ions discourage one or more cellular proteins from destroying microorganisms. The images of activity and clime of restraint are shown in Fig-5.

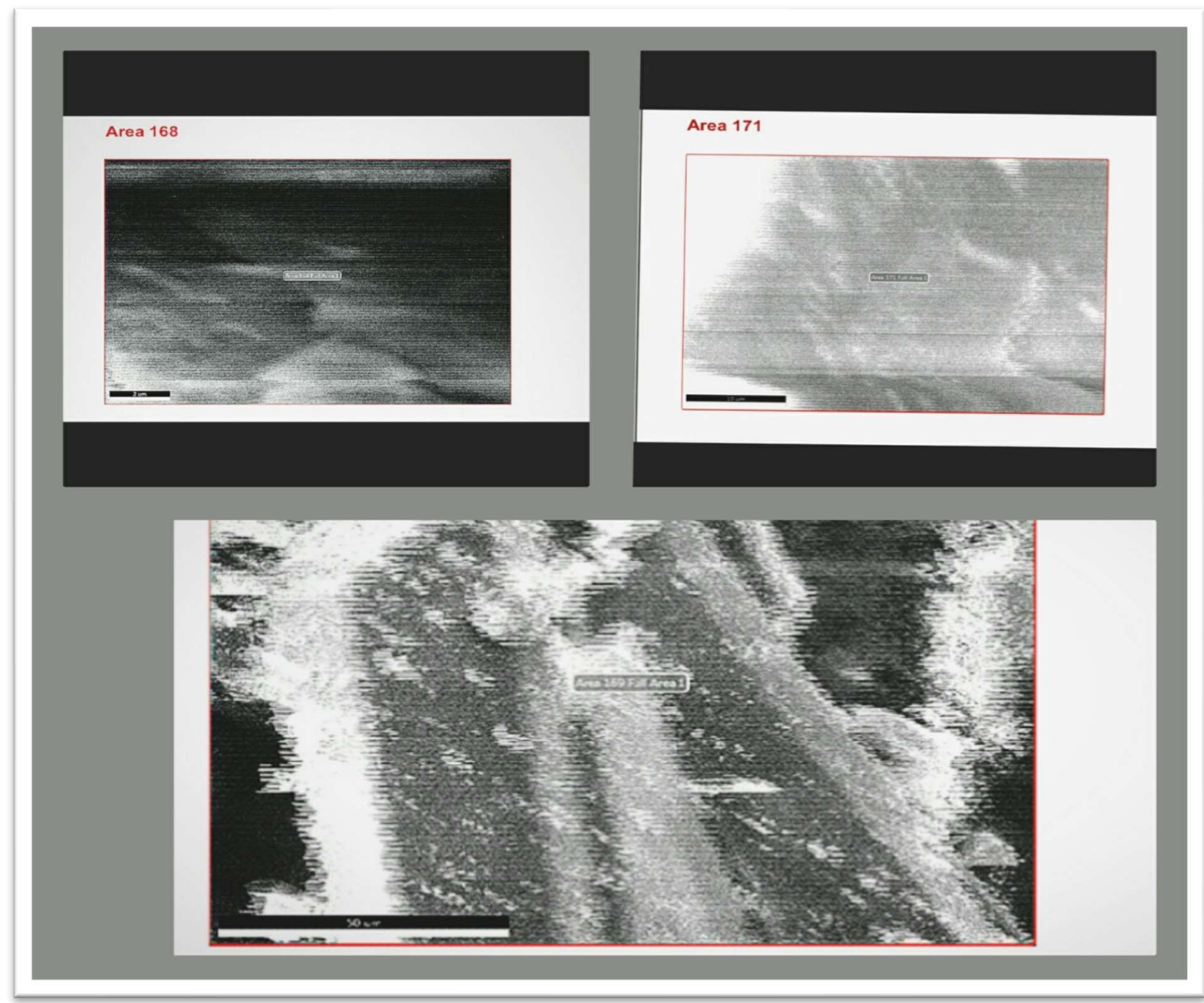

Fig.-5: SEM Images of (Area-168) Primary Ligand [TMBAAP]with(2 $\mu \mathrm{nm}$ ) Size, (Area-171) Image of Metal Complex Ni[TMBAAP] with $(10 \mu \mathrm{nm})$ Size,(Area-169) Secondary Ligand along with Metal Complex Ni[TMBAAPT]with $(50 \mu \mathrm{nm})$ 1412 
RASĀYAN J. Chem.

Vol. 14 | No. 2 |1408-1414| April - June | 2021

Table-3: Activity of Microorganism

\begin{tabular}{c|c|c|c|c}
\hline \multirow{2}{*}{ Compound } & \multicolumn{2}{|c|}{ Bacteria } & \multicolumn{2}{c}{ Fungi } \\
\cline { 2 - 5 } & $\begin{array}{c}\text { Staphylococcus } \\
\text { aureus }\end{array}$ & $\begin{array}{c}\text { Salmonella } \\
\text { Typhi }\end{array}$ & $\begin{array}{c}\text { Candida } \\
\text { albicans }\end{array}$ & $\begin{array}{c}\text { Aspergillus } \\
\text { Fumigatus }\end{array}$ \\
\hline $\begin{array}{c}\text { Primary } \\
\text { Ligand[TMBAAP] }\end{array}$ & $8 \mathrm{~mm}$ & $8 \mathrm{~mm}$ & $11 \mathrm{~mm}$ & $9 \mathrm{~mm}$ \\
\hline $\begin{array}{c}\text { Mixed Ligand } \\
\text { [TMBAAPT] }\end{array}$ & $17 \mathrm{~mm}$ & $17 \mathrm{~mm}$ & $15 \mathrm{~mm}$ & $20 \mathrm{~mm}$ \\
\hline
\end{tabular}

Where,

Marginally effective $=$ restraint clime $(6-9 \mathrm{~mm})$

Adequately effective $=$ restraint clime $(9-12 \mathrm{~mm})$

Highly effective $=$ restraint clime $($ more than $12 \mathrm{~mm})$

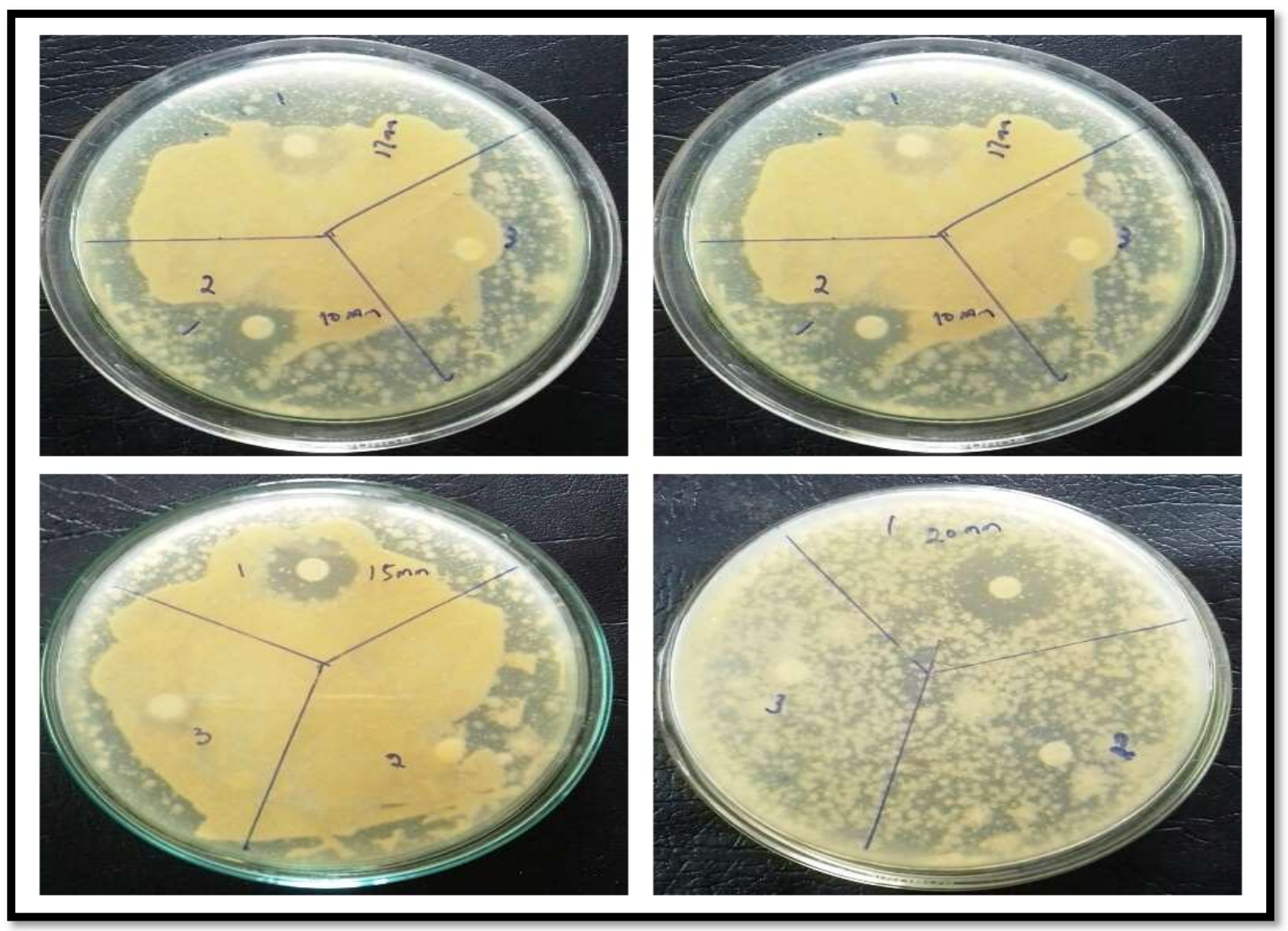

Fig.-5: Restraint Clime of Microorganisms

\section{CONCLUSION}

In the present paper, the author described the synthesis of mixed ligand complex containing (ML) [3, 4, 5Trimethoxy benzalidine-4-amino-1,5-dimethyl-2-phenyl-1-H-Pyrazol-2-H-One-2-amino-3-1-H-indol-3ylpropanoic acid] with $\mathrm{Ni}(\mathrm{II})$ metal. The ligand and its complex are soluble in water and DMSO and it exhibits octahedral geometry. The anti-fungal and anti-bacterial screening assignment were inspected against Staphylococcus aureus, Salmonella typhi, Candida albicans and Aspergillus fumigatus. The resulted data displayed that the mixed ligand complex showed potential activity against microbes examined.

\section{ACKNOWLEDGMENT}

The authors would like to express sincere gratitude to the Department of Chemistry, Sri Krishnadevaraya University for aiding the present investigation study and providing facilities throughout research work. 
RASĀYAN J. Chem.

Vol. 14 | No. 2 |1408-1414| April - June | 2021

\section{REFERENCES}

1. Wail Al Zoubi, Abbas Ali Salih, Al-Hamdani, Susan Duraid Ahmed, Young Gun Ko, Applied Organometallic Chemistry, 31,11(2017), DOI:10.1002/aoc.3895

2. M. M El-ajaily and A. A. Maihub, Al-mukhtar, Hindawi Journal of Chemistry, 10, 70(2013) DOI: $10.1155 / 2013 / 479343$

3. W. Rehman, F.Saman, Iftikhar Ahmad, Russain Journal of Coordination Chemistry 34(9), 678(2008), DOI:10.1134/S107032840809008X

4. K. Sudhakar Babu, P. Malleswar Reddy, V. Krishna Murthy Naik and K. Ramanjaneyulu, International Journal of Pharmaceutical Sciences \& Research, 10(9), 396(2019), DOI:10.13040/IJPSR.0975-8232

5. R. H. Taha, Z.A. El-Shafiey, A. A. Salman, Journal of Molecular Structure, 1181, 536(2018), DOI: $10.1016 /$ molstruc.2018.12.055

6. R. Herandez-Molina, P. A. Abramov, J. Gonzalez-platas, S. Oramas-Royo, A. Estevez Braun, M. Guerra Rodriguez, H. Aranda Tavio, B. Guerra, L. Fernandez, Polyhedron, 165, 73(2019), DOI: $10.1016 /$ j.poly.2019.114280

7. L- Hui Yu, Wei Zhang, QingYu, Fu-Ping Huang, He-Dong Bian and Hong Liang,Molecules, 22(10), 1772(2017), DOI: 10.3390/molecules22101772

8. M. Hasanzadeh Esfahani, H. Iranmanesh, J. E. Beves, M. Kaur, J. P. Jasinski, M. Behzad, Journal of Coordination Chemistry, 72(14), 2326(2019), DOI:10.1080/00958972.2019.1643846

9. V. Sheela Violet Rani, Prabakaran Eswaran, D. Jesudurai, Asian Journal of Chemistry, 28(12), 2685(2016), DOI: 10.14233/ajchem.2016.20069

10. Saba H. Mahdi and Le Kaak Abdul Kareem, Oriental Journal of Chemistry, 34(3), 1565(2018), DOI: $10.13005 / \mathrm{ojc} / 340349$

11. L. Subha, C. Balakrishnan, S. Thalamuthu and M. A. Neelakantan, Journal of Coordination Chemistry, 68(6), 1021(2015), DOI:10.1080/00958972.2015.1008466

12. Pallavi Jain, Dinesh Kumar, Sulekh Chandra, Namita Misra, Applied Orgaometallic Chemistry, 33(8), e5371(2019), DOI: 10.1002/aoc .5371

13. N. Raman, S. Johnson Raja and Sakthivel, Journal of Coordination Chemistry, 62(5), 691(2009), DOI: $10.1080 / 00958970802326179$

14. V. B. Badwaik, R. D. Deshmukh and A. S. Aswar, Journal of Coordination Chemistry, 62(12),2037(2009), DOI: 10.1080/00958970902741244

15. Sellamuthu Kathiresan, Subramanian Mugesh and Jamespandi Anaraj, New Journal of Chemistry 40 (2016), DOI:10.1039/C6NJ03501A

[RJC-6253/2020] 